\title{
PENGARUH ELECTRONIC PROCUREMENT TERHADAP GOOD GOVERNANCE PADA PEMERINTAH PROVINSI BALI
}

\author{
I Made Budi Adiana ${ }^{1}$ \\ I Nyoman Mahaendra Yasa ${ }^{2}$ \\ I Gede Wardana ${ }^{3}$ \\ ${ }^{1,2,3}$ Fakultas Ekonomi dan Bisnis Universitas Udayana (Unud), Bali, Indonesia \\ Email : budiadiana18@gmail.com
}

\begin{abstract}
ABSTRAK
Terwujudnya pemerintahan yang baik merupakan prasyarat pemerintahan untuk mewujudkan aspirasi masyarakat dan upaya mencapai cita-cita bangsa dan negara. Salah satu upaya pemerintah untuk mewujudkannya adalah dengan pengadaan barang/jasa secara elektronik atau electronic procurement. Namun demikian, masih terdapat masalah diantaranya kualitas layanan belum optimal dan masih terjadi lelang gagal dengan pemberlakuan e-procurement. Penelitian ini bertujuan menganalisis pengaruh electronic procurement terhadap good governance pada Pemerintah Provinsi Bali. Tujuan dari penelitian ini adalah untuk menganalisis pengaruh langsung dan tidak langsung antara variabel Electronic Procurement, Komitmen Pegawai, Kualitas Layanan Pengadaan, dan Good Governance pada Pemerintah Provinsi Bali. Teknik analisis yang digunakan adalah teknik deskriptif dan persamaan struktural dengan menggunakamn alternatif SEM PLS. Hasil dari penelitian ini menunjukkan bahwa variabel Electronic Procurement dan Komitmen Pegawai berpengaruh positif dan signifikan terhadap Kualitas Layanan Pengadaan dengan nilai $R$-Square sebesar 0,596. Selain itu, variabel Electronic Procurement, Komitmen Pegawai, dan Kualitas Layanan Pengadaan juga memiliki pengaruh positif dan signifikan terhadap Good Governance dengan $R$-Square sebesar 0,723 .
\end{abstract}

Kata kunci: Electronic Procurement, Komitmen Pegawai, Kualitas Layanan Pengadaan, dan Good Governance

\begin{abstract}
The realization of good governance is a prerequisite for the government in realizing the aspirations of the people and achieving the ideals of the nation and state. One of the government's efforts to make it happen is by procurement of goods / services electronically or electronic procurement. Nevertheless, there are still problems such as the quality of service is not optimal and there is still auction failed with the implementation of e-procurement. This study analyze the influence of electronic procurement on good governance in Bali Provincial Government. This study aims to analyze the direct and indirect influence between Electronic Procurement variables, Employee Commitment, Quality of Procurement Service, and Good Governance in Bali Provincial Government. In this research used descriptive analysis technique and structural equation with SEM alternative PLS. The results of the research shows that the variable of Electronic Procurement and Employee Commitment have positive and significant effect on Quality of Procurement Service with R-Square value of 0,596. In addition, the varibles of Electronic Procurement, Employee Commitment, and Quality of Procurement Service also have a positive and significant effect on Good Governance with R-Square value of 0.723 .
\end{abstract}

Keywords: Electronic Procurement, Employee Commitment, Quality of Procurement Service, and Good Governance 


\section{PENDAHULUAN}

Good governance yang merupakan landasan nilai penyelenggaraan pemerintahan saat ini pada prinsipnya menekankan tentang pentingnya kolaborasi dalam kesetaraan dan kesimbangan antara sektor publik, sektor swasta dan masyarakat. Good governance ini mengisyaratkan adanya pandangan atau paradigma baru administrasi publik yang disebut dengan tata kepemerintahan yang baik (good governance). Paradigma good governance menekankan arti penting kesetaraan antara institusi negara, swasta dan masyarakat. Oleh karena itu konsep good governance ini ditujukan untuk meningkatkan peranan dan keterlibatan masyarakat dalam proses pembangunan pada umumnya, yang dimulai dari tahap perencanaan pembangunan, implementasi dan evaluasi.

Sebagaimana agenda pemerintah saat ini adalah reformasi birokrasi, yaitu dalam pelaksanaannya melakukan perubahan yang mendasar organisasi pemerintah atau birokrasi menghadapi lingkungan yang berubah, sehingga perlu ada tindakan dalam melakukan adaptasi dan antisipasi supaya dapat memberikan pelayanan publik terbaik. Pemerintah Provinsi Bali sangat fokus dalam pencapaian prinsip-prinsip tata kelola pemerintahan yang baik. Pemerintah Provinsi Bali sebagaimana tertuang dalam Peraturan Daerah Provinsi Bali Nomor 1 Tahun 2014 tanggal 10 Maret 2014 tentang Rencana Pembangunan Jangka Menengah Daerah Provinsi Bali Tahun 2013-2018 telah menetapkan visi Provinsi Bali yaitu Bali Mandara, Bali yang maju, aman, damai, dan sejahtera.

Visi pembangunan Provinsi Bali jangka menengah ditempuh melalui misi pembangunan daerah. Sasaran yang akan dicapai pada tujuan misi Pemerintah 
Provinsi Bali adalah terwujudnya good governance. Strategi yang digunakan yaitu mengintensifkan pelaksanaan tata kelola kepemerintahan yang baik. Strategi ini merupakan upaya untuk mendukung capaian sasaran yang akan dilakukan pada tujuan misi pertama yaitu melalui implementasi pelayanan publik.

Permasalahan pelayanan publik yang dihadapi pemerintah saat ini, mendorong pemerintah menciptakan pelayanan publik yang transparan. Salah satu upaya pemerintah adalah diterapkannya e-government pada setiap instansi ataupun lembaga di tingkat pusat dan daerah. Seperti dijelaskan dalam Indrajit (2005), konsep atau e-government bukanlah inisiatif mudah dan murah. Egovernment merupakan sarana atau alat yang menghasilkan kemudahan pelayanan publik kepada masyarakat.

Salah satu bentuk e-government yang telah diterapkan pemerintah adalah aplikasi e-procurement, suatu sistem pengadaan barang dan jasa publik yang dikelola secara elektronik berbasis web. Pertimbangan yang mendasari kebijakan ini adalah kurang efisiennya sistem pengadaan barang dan jasa secara manual seperti yang selama ini dilakukan sebelum diterapkannya e-procurement. Penerapan e-procurement mengacu pada Peraturan Presiden No. 54 pasal 131 ayat (1) Tahun 2010 tentang pengadaan barang dan jasa pemerintah wajib melaksanakan pengadaan secara elektronik berikut perubahan terakhir Perpres No. 4 Tahun 2015.

Pengadaan barang dan jasa secara elektronik di Pemerintah Provinsi Bali dioperasikan melalui Layanan Pengadaan Secara Elektronik (LPSE) Pemerintah Provinsi Bali. Masalah-masalah umum terjadi di daerah lain yang berhubungan 
dengan proses pengadaan barang/jasa juga terjadi pada Pemerintah Provinsi Bali. Pengadaan barang/jasa yang sebelumnya secara manual banyak mendapatkan keluhan masyarakat, utamanya dari sisi transparansi yang dapat dilihat dari setiap tahapan atau proses pengadaan barang/jasa. Situasi ini menunjukkan kemungkinan pada pengadaan yang dilakukan secara manual terjadi tindakan KKN. Sejak tahun 2010 Pemerintah Provinsi Bali dalam memenuhi kebutuhan lembaga akan barang dan jasa mulai mengaplikasikan sistem e-procurement dalam setiap proses pengadaannya.

Pada permulaan tahun 2017, Direktorat Penelitian dan Pengembangan Komisi Pemberantasan Korupsi (KPK) bersama Badan Pusat Statistik (BPS) melakukan Penilaian Integritas (Integrity Assessment) pada Pemerintah Provinsi Bali. Penilaian tersebut masih menemukan beberapa permasalahan yang perlu mendapatkan perhatian yaitu pada penilaian komponen transparansi layanan publik yang dilaksanakan dan ditemukan adanya penyelewengan pengadaan barang dan jasa yang tidak sesuai perencanaan dan terdapatnya proyek fiktif. Hal ini dapat menimbulkan ketidakpercayaan publik terhadap penyelenggaraan pemerintahan. Untuk itu diperlukan perbaikan setiap sektor sehingga penyelenggaraan pemerintahan dapat menunjukkan tata kelola yang baik.

Dengan adanya permasalahan-permasalahan yang terjadi di atas, maka penulis melakukan penelitian yang berkaitan dengan Pengaruh Electronic procurement terhadap Good governance pada Pemerintah Provinsi Bali.

Berdasarkan uraian tersebut rumusan masalah penelitian ini adalah: 1) Bagaimanakah pengaruh Electronic procurement dan Komitmen Pegawai 
terhadap Kualitas Layanan Pengadaan pada Pemerintah Provinsi Bali? 2) Bagaimanakah pengaruh Electronic procurement, Komitmen Pegawai dan Kualitas Layanan Pengadaan terhadap Good governance pada Pemerintah Provinsi Bali? 3) Adakah pengaruh tidak langsung Electronic procurement dan Komitmen Pegawai terhadap Good governance melalui Kualitas Layanan Pengadaan pada Pemerintah Provinsi Bali?

Tujuan dari penelitian yang dilakukan adalah untuk menganalisis pengaruh Electronic procurement dan Komitmen Pegawai terhadap Kualitas Layanan Pengadaan pada Pemerintah Provinsi Bali, untuk menganalisis pengaruh Electronic procurement, Komitmen Pegawai dan Kualitas Layanan Pengadaan terhadap Good governance pada Pemerintah Provinsi Bali, dan untuk menganalisis pengaruh tidak langsung Electronic procurement dan Komitmen Pegawai terhadap Good governance melalui Kualitas Layanan Pengadaan pada Pemerintah Provinsi Bali

\section{METODE PENELITIAN}

Penelitian ini dilaksanakan di Provinsi Bali. Populasi penelitian ini adalah penyedia barang/jasa yang pernah mengikuti dan memenangkan e-procurement serta mengikuti seluruh tahapan pengadaan barang/jasa pada Pemerintah Provinsi Bali. Teknik pengambilan sampel atas responden dilakukan secara systematic random sampling atau acak secara sistematis dan Jumlah sampel adalah sebanyak 90 sampel. 
Variabel pengelolaan e-procurement dan komitmen pegawai dalam penelitian ini merupakan variabel eksogen. Kualitas layanan pengadaan merupakan variabel antara karena berfungsi ganda yaitu sebagai variabel independen dan sebagai variabel dependen pada hubungan lain. Variabel good governance merupakan variabel endogen.

Definisi operasional variabel adalah sebagai berikut:

1) E-procurement atau pengadaan secara elektronik adalah pengadaan barang/jasa yang dilaksanakan dengan menggunakan teknologi informasi dan transaksi elektronik sesuai dengan ketentuan perundang-undangan. Variabel ini menggunakan indikator berdasarkan Peraturan Presiden Nomor 54 Tahun 2010 tentang Pengadaan Barang/Jasa Pemerintah beserta perubannya dan aturan turunannya yang juga digunakan saat penelitian oleh Rieska Maharani \& Ardi Hamzah (2008) yaitu: efisien, adil/tidak diskriminatif, dan akuntabel.

2) Komitmen pegawai adalah keinginan anggota organisasi untuk tetap mempertahankan keanggotaannya dalam organisasi dan bersedia berusaha keras bagi pencapaian tujuan organisasi (Sopiah, 2008). Pengukuran komitmen pegawai pada organisasi dari skala Mowday yang juga digunakan saat penelitian oleh Hidayat, M. (2010) yaitu: Affective, Continuance dan Normative.

3) Kualitas Layanan Pengadaan adalah keunggulan pelayanan yang diberikan kepada pengguna layanan untuk mendapatkan barang dan jasa yang diperlukan sesuai dengan kebutuhan penggunaannnya yang telah ditentukan, dilihat dari kualitas, kuantitas, waktu pengiriman dan harga yang terjangkau 
(Valerie, A. dkk. 1990). Variabel ini menggunakan indikator reability, responsiveness, dan assurance yang juga digunakan saat penelitian oleh Heryanto, Y. (2014).

4) Good governance adalah penyelenggaraan pemerintahan yang solid dan bertanggung jawab, efisien, dan efektif, dengan menjaga kesinergian interaksi antara domain-domain negara, sektor swasta, dan masyarakat. Indikator yang digunakan berdasarkan prinsip-prinsip menurut United Nations Development Planning (UNDP) dalam Sedarmayanti (2004) yang juga digunakan saat penelitian oleh Yanto Heryanto (2014) yaitu: transparansi, daya tanggap, dan efektif dan efisien.

Data yang digunakan dalam penelitian ini adalah data kuantitatif dan kualitatif. Data kuantitatif antara lain e-procurement, komitmen pegawai, kualitas layanan pengadaan, dan good governance yang diukur menggunakan skala likert. Data kualitatif antara lain penjelasan yang relevan tentang karakteristik lokasi serta permasalahan-permasalahan e-procurement di Provinsi Bali. Penelitian ini menggunakan data primer yang diperoleh dengan kuisioner penelitian.

Teknik analisis data yang dipergunakan untuk mengetahui pengaruh variabel yang diamati dalam penelitian ini adalah Partial Least Square (PLS) component based Structural Equation Model (SEM). Model SEM adalah teknik statistik yang memungkinkan pengujian rangkaian hubungan yang kompleks secara simultan serta berjenjang. Berdasarkan kajian teoritis dan empiris dapat dibuat hubungan antar variabel pada Gambar 1. 


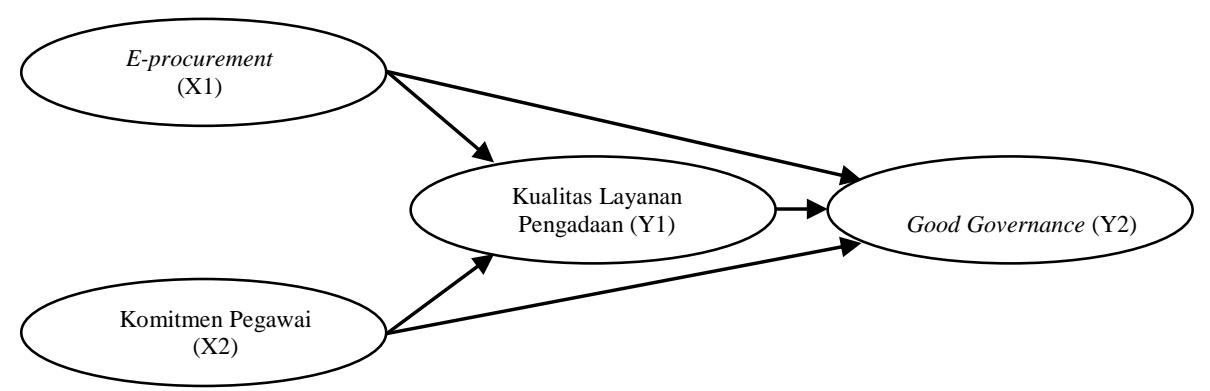

Gambar 1

Model Analisis Jalur

Teknik PLS menspesifikasikan hubungan antar variabel, yaitu: outer model, inner model, serta pengaruh tidak langsung yang diuraikan berikut ini:

\section{1) Outer model}

Outer model atau measurement model yaitu model pengukuran yang merupakan hubungan antara indikator dengan variabel latennya. Sesuai Gambar 2.1, terdapat empat model pengukuran yang semuanya merupakan indikator reflektif, yaitu: e-procurement, komitmen pimpinan, kualitas layanan pengadaan, dan good governance.

Evaluasi outer model dilakukan dengan tiga cara, yaitu:

(1) Convergent Validity (CV) pada indikator reflektif yaitu dengan melihat korelasi atau loading antara variabel terukur dengan variabel latennya.

(2) Discrimanant Validity (DV) pada indikator reflektif yaitu dengan melihat crossloading terhadap konstruk atau latennya.

(3) Composite Reliability ( $\rho \mathrm{c})$ digunakan untuk indikator reflektif yang bertujuan untuk mengukur konsistensi internal suatu konstruk, di samping Cronbach Alpha yang sering digunakan. 
2) Inner model

Dalam PLS inner model menggambarkan hubungan antar variabel laten berdasarkan substansi teori. Model persamaan sesuai dengan Gambar 2.1 adalah:

$\mathrm{Y} 1=\beta 1 \mathrm{X} 1+\beta 2 \mathrm{X} 2+\varepsilon 1$

$\mathrm{Y} 2=\beta 3 \mathrm{X} 1+\beta 4 \mathrm{X} 2+\beta 5 \mathrm{Y} 1+\varepsilon 2$

Keterangan:

$\mathrm{X} 1=$ E-procurement

$\mathrm{X} 2$ = Komitmen pegawai

$\mathrm{Y} 1=$ Kualitas Layanan Pengadaan

$\mathrm{Y} 2=$ Good Governance

$\beta 1, \beta 2, \ldots \beta 5=$ koefisien jalur

$\varepsilon 1, \varepsilon 2=$ inner residual

Evaluasi terhadap inner model dilakukan dengan melihat besarnya koefisien jalur strukturalnya, dan juga nilai uji t statistiknya yang diperoleh dengan metode bootstrapping. Di samping itu juga diperhatikan $\mathrm{R}^{2}$ untuk variabel laten dependen. Selain $\mathrm{R}^{2}$ model PLS juga dapat dievaluasi predictive prevelance melalui Stone-Geiser Q Square test (Ghozali, 2011).

3) Pengaruh tidak langsung

Untuk mengetahui ada atau tidaknya peran variabel antara atas pengaruh variabel independen terhadap variabel dependen, PLS akan otomatis mengeluarkan hasilnya melalui indirect effect atau pengaruh tidak langsung.

\section{HASIL DAN PEMBAHASAN}

Berdasarkan data yang diperoleh dari hasil penelitian, dapat dijelaskan mengenai karakteristik penyedia barang/jasa. Karakteristik penyedia barang/jasa dapat dilihat melalui demografi penyedia barang/jasa. Demografi tersebut 
digunakan untuk mengetahui gambaran umum tentang penyedia barang/jasa pada Pemerintah Provinsi Bali. Demografi responden pada penelitian ini meliputi: jenis kelamin, umur, pendidikan, dan katagori usaha.

Responden didominasi oleh penyedia barang/jasa berjenis kelamin lakilaki yaitu sebanyak $76,67 \%$ sedangkan penyedia barang/jasa berjenis kelamin perempuan yaitu sebanyak 23,33\%. Hal ini membuktikan bahwa dunia usaha dalam urusan bisnis masih didominasi oleh penyedia barang/jasa yang berjenis kelamin laki-laki. Demografi responden berdasarkan umur lebih didominasi oleh responden yang berumur 41 sampai 50 tahun yaitu sebesar 47,78\%. Untuk jenjang pendidikan responden diketahui bahwa sebanyak $70,00 \%$ memiliki jenjang pendidikan S1/D4, sebanyak 12,22\% memiliki jenjang pendidikan S2, sebanyak $10 \%$ memiliki jenjang pendidikan SLTA, dan sisanya sebesar 7,78\% memiliki jenjang pendidikan Diploma. Sementara itu, responden pada Pemerintah Provinsi Bali didominasi responden yang berkatagori usaha kecil sebesar 63,33\%, katagori usaha besar sebesar 20,00\% dan katagori usaha menengah sebesar 16,67\%.

Persepsi responden terhadap variabel E-procurement (X1) terkonsentrasi pada skor nilai 4 dan 5 dimana keseluruhan memiliki rataan skor sebesar 4,35. Hal ini berarti bahwa e-procurement berada pada tingkat sangat baik. Namun demikian ada indikator yang rataan skornya masih berada di bawah rata-rata yaitu indikator Adil/Tidak Diskriminatif (X1.2) dengan rataan skor sebesar 4,24. Indikator yang memiliki rataan skor paling tinggi yaitu Akuntabel (X1.3) dengan rataan skor sebesar 4,40. Indikator Efisien (X1.1) dengan rataan skor 4,39. 
Persepsi responden terhadap variabel Komitmen Pegawai (X2) terkonsentrasi pada skor nilai 4 dan 5 dan secara keseluruhan memiliki rataan skor sebesar 4,23. Ini berarti bahwa Komitmen Pegawai berada pada tingkat sangat baik. Namun demikian ada indikator yang rataan skornya masih berada di bawah rata-rata yaitu indikator Komitmen Berkesinambungan (X2.2) dengan rataan skor sebesar 4,15. Indikator yang memiliki rataan skor paling tinggi yaitu Komitmen Normatif (X2.3) dengan rataan skor sebesar 4,31.

Persepsi responden terhadap Kulaitas Layanan Pengadaan (Y1) terkonsentrasi pada skor nilai 4 dan 5 dan secara keseluruhan memiliki rataan skor sebesar 4,25. Ini berarti bahwa Kualitas Layanan Pengadaan berada pada tingkat sangat baik. Namun demikian ada indikator yang rataan skornya masih berada di bawah rata-rata yaitu indikator Reability (Y1.1) dengan rataan skor sebesar 4,24 dan Assurance (Y1.3) dengan rataan skor sebesar 4,20. Indikator yang memiliki rataan skor paling tinggi yaitu Responsiveness (Y1.2) dengan rataan skor sebesar 4,31 .

Persepsi responden terhadap variabel good governance (Y2) terkonsentrasi pada skor nilai 4 dan 5 dan secara keseluruhan memiliki rataan skor sebesar 4,17. Ini berarti bahwa Good Governance berada pada tingkat baik. Namun demikian ada indikator yang rataan skornya masih berada di bawah rata-rata yaitu indikator Daya Tanggap (Y2.2) dengan rataan skor sebesar 3,94. Indikator yang memiliki rataan skor paling tinggi yaitu Efektif dan Eisieni (Y2.3) dengan rataan skor sebesar 4,35. 
Penelitian ini menguji pengaruh Electronic Procurement terhadap Good Governance pada Pemerintah Provinsi Bali dengan Kualitas Layanan Pengadaan sebagai variabel mediasi. Secara keseluruhan full model PLS pada Gambar 2.

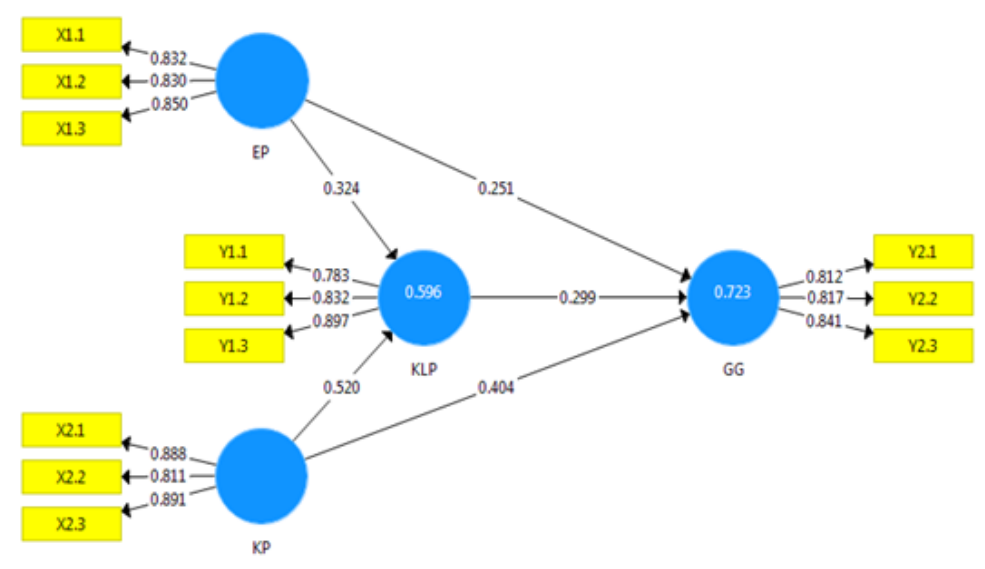

Gambar 2

Full Model dari Pengaruh Electronic Procurement Terhadap Good Governance Pada Pemerintah Provinsi Bali

1) Evaluasi Outer Model atau Measurement Model

Berdasarkan hasil perhitungan convergent validity, semua indikator yang membentuk konstruk e-procurement (X1), Komitmen Pegawai (X2), Kualitas Layanan Pengadaan (Y1), dan Good Governance (Y2) secara statistik signifikan dengan nilai $p$ value sebesar 0,000 thitung lebih besar dari 1,96. Nilai loading semuanya di atas 0,5 berarti bahwa konstruk yang dibuat sudah memenuhi syarat convergent validity. Tabel 1 menyajikan hasil output PLS mengenai convergent validity. 
Tabel 1

Outer Loading Indikator Terhadap Konstruk

Electronic Procurement (X1), Komitmen Pegawai (X2), Kualitas Layanan Pengadaan (Y1), dan Good Governance (Y2) Pemerintah Provinsi Bali

\begin{tabular}{ccccc}
\hline $\begin{array}{c}\text { Hubungan } \\
\text { Antar Variabel }\end{array}$ & Loading & $\begin{array}{c}\text { Standar } \\
\text { Deviation }\end{array}$ & T Statistics & P Values \\
\hline $\mathbf{1}$ & $\mathbf{2}$ & $\mathbf{3}$ & $\mathbf{4}$ & $\mathbf{5}$ \\
\hline $\mathrm{X} 1.1 \leftarrow \mathrm{X} 1$ & 0,832 & 0,033 & 24,922 & 0,000 \\
$\mathrm{X} 1.2 \leftarrow \mathrm{X} 1$ & 0,830 & 0,049 & 17,054 & 0,000 \\
$\mathrm{X} 1.3 \leftarrow \mathrm{X} 1$ & 0,850 & 0,031 & 27,735 & 0,000 \\
\hline $\mathrm{X} 2.1 \leftarrow \mathrm{X} 2$ & 0,888 & 0,038 & 23,499 & 0,000 \\
$\mathrm{X} 2.2 \leftarrow \mathrm{X} 2$ & 0,811 & 0,055 & 14,857 & 0,000 \\
$\mathrm{X} 2.3 \leftarrow \mathrm{X} 2$ & 0,891 & 0,034 & 26,376 & 0,000 \\
\hline $\mathrm{Y} 1.1 \leftarrow \mathrm{Y} 1$ & 0,783 & 0,055 & 14,250 & 0,000 \\
$\mathrm{Y} 1.2 \leftarrow \mathrm{Y} 1$ & 0,832 & 0,048 & 17,343 & 0,000 \\
$\mathrm{Y} 1.3 \leftarrow \mathrm{Y} 1$ & 0,897 & 0,023 & 39,765 & 0,000 \\
\hline $\mathrm{Y} 2.1 \leftarrow \mathrm{Y} 2$ & 0,812 & 0,047 & 17,216 & 0,000 \\
$\mathrm{Y} 2.2 \leftarrow \mathrm{Y} 2$ & 0,817 & 0,044 & 18,453 & 0,000 \\
$\mathrm{Y} 2.3 \leftarrow \mathrm{Y} 2$ & 0,841 & 0,029 & 28,630 & 0,000 \\
\hline Sumber $:$ Data primer $(2017)$ & & &
\end{tabular}

Validitas suatu konstruk juga dapat dilihat dari Discriminan Validity (DV) pada indikator reflektif yaitu dengan melihat Cross Loading indikator terhadap konstruk atau latennya. Discriminant Validity $(D V)$ bagus apabila indikatornya memiliki Cross Loading pada konstruknya lebih besar dibandingkan dengan konstruk lainnya.

Hasil Cross Loading indikator terhadap konstruk Electronic Procurement (X1), Komitmen Pegawai (X2), Kualitas Layanan Pengadaan (Y1), dan Good Governance (Y2) Pemerintah Provinsi Bali terlihat seperti pada Tabel 2.

Berdasarkan hasil pada Tabel 2 dapat dinyatakan bahwa Discriminant Validity $(D V)$ telah terpenuhi dan Cross Loading juga telah terpenuhi dengan baik. Indikatornya memiliki Cross Loading lebih besar dari pada konstruk lainnya. 
Tabel 2

Cross Loading Indikator Terhadap Konstruk

Electronic Procurement (X1), Komitmen Pegawai (X2), Kualitas Layanan Pengadaan (Y1), dan Good Governance (Y2) Pemerintah Provinsi Bali

\begin{tabular}{l|c|c|c|c|c}
\hline \multirow{2}{*}{ Konstruk } & $\begin{array}{c}\text { Indi- } \\
\text { kator }\end{array}$ & $\begin{array}{c}\text { Electronic } \\
\text { Procurement }\end{array}$ & $\begin{array}{c}\text { Komitmen } \\
\text { Pegawai }\end{array}$ & $\begin{array}{c}\text { Kualitas } \\
\text { Layanan } \\
\text { Pengadaan }\end{array}$ & $\begin{array}{c}\text { Good } \\
\text { Governance }\end{array}$ \\
\cline { 3 - 6 } $\mathbf{1}$ & $\mathbf{2}$ & $\mathbf{( X 1 )}$ & $\mathbf{( X 2 )}$ & $\mathbf{( Y 1 )}$ & $\mathbf{( Y 2 )}$ \\
\hline Electronic & $\mathrm{X} 1.1$ & $\mathbf{0 . 8 3 2}$ & 0,613 & 0,578 & 0.576 \\
Procurement (X1) & $\mathrm{X} 1.2$ & $\mathbf{0 , 8 3 0}$ & 0,432 & 0,457 & 0,592 \\
& $\mathrm{X} 1.3$ & $\mathbf{0 , 8 5 0}$ & 0,580 & 0,620 & 0,620 \\
\hline Komitmen & $\mathrm{X} 2.1$ & 0,627 & $\mathbf{0 . 8 8 8}$ & 0,635 & 0,727 \\
Pegawai (X2) & $\mathrm{X} 2.2$ & 0,485 & $\mathbf{0 , 8 1 1}$ & 0,556 & 0,594 \\
& $\mathrm{X} 2.3$ & 0,569 & $\mathbf{0 , 8 9 1}$ & 0,697 & 0,708 \\
\hline Kualitas Layanan & $\mathrm{Y} 1.1$ & 0.451 & 0.533 & $\mathbf{0 . 7 8 3}$ & 0.611 \\
Pengadaan (Y1) & $\mathrm{Y} 1.2$ & 0,578 & 0,581 & $\mathbf{0 , 8 3 2}$ & 0,632 \\
& $\mathrm{Y} 1.3$ & 0,628 & 0,713 & $\mathbf{0 , 8 9 7}$ & 0,670 \\
\hline Good Governance & $\mathrm{Y} 2.1$ & 0.527 & 0.650 & 0.549 & $\mathbf{0 . 8 1 2}$ \\
(Y2) & $\mathrm{Y} 2.2$ & 0,577 & 0,547 & 0,569 & $\mathbf{0 , 8 1 7}$ \\
& $\mathrm{Y} 2.3$ & 0,645 & 0,727 & 0,738 & $\mathbf{0 , 8 4 1}$ \\
\hline Sumber : Datapryyyyy
\end{tabular}

Sumber : Data primer (2017)

Kelayakan konstruk yang dibuat selain dilihat dari DV juga dapat dilihat melalui Average Variance Extracted (AVE), Cronbach's Alpha, dan Composite Reliability. Umumnya indikator ini digunakan untuk indikator reflektif yang bertujuan mengukur konsistensi internal suatu konstruk.

Berdasarkan Tabel 3 dapat diketahui bahwa Electronic Procurement (X1), Komitmen Pegawai (X2), Kualitas Layanan Pengadaan (Y1), dan Good Governance (Y2) Pemerintah Provinsi Bali sangat baik karena memiliki Discriminant Validity (DV) lebih besar dari 0,5 dimana Average Variance Extracted (AVE), Composite Reliability, dan Cronbach's Alpha di atas 0,6. 
Tabel 3

Average Variance Extracted (AVE), Composite Reliability, dan Cronbach's Alpha Konstruk Electronic Procurement (X1), Komitmen Pegawai (X2), Kualitas Layanan Pengadaan (Y1), dan Good Governance (Y2) Pemerintah Provinsi Bali

\begin{tabular}{lcccc}
\hline Variabel / Konstruk & $\begin{array}{c}\text { Average } \\
\text { Variance } \\
\text { Extracted }\end{array}$ & Akar AVE & $\begin{array}{c}\text { Composite } \\
\text { Reliability }\end{array}$ & $\begin{array}{c}\text { Cronbach's } \\
\text { Alpha }\end{array}$ \\
\hline 1 & $\mathbf{2}$ & $\mathbf{3}$ & $\mathbf{4}$ & $\mathbf{5}$ \\
\hline Electronic Procurement (X1) & 0,702 & 0,838 & 0,876 & 0,788 \\
Komitmen Pegawai (X2) & 0,747 & 0,864 & 0,898 & 0,830 \\
Kualitas Layanan Pengadaan & 0,703 & 0,838 & 0,876 & 0,787 \\
Good Governance (Y2) & 0,678 & 0,823 & 0,863 & 0,765 \\
\hline Sumber: Data primer(2017) & & & &
\end{tabular}

2) Pengujian Model Struktural (Inner Model)

Hasil pengujian Inner Model dapat melihat hubungan antar konstruk dengan cara membandingkan nilai signifikansi dan $R$-Square dari model penelitian (Ghozali, 2011). Nilai $R$-Square dapat diklasifikasikan menjadi 3 (tiga) jenis yaitu $0,00-0,19=$ lemah; $0,19-0,67=$ moderat; dan $0,67-1,00=$ kuat .

Tabel 4

Nilai $R$-Square

\begin{tabular}{|c|c|c|c|}
\hline No & Variabel Dependen & R-Square & Keterangan \\
\hline 1 & 2 & 3 & \\
\hline 1 & Kualitas Layanan Pengadaan (Y1) & 0,596 & Moderat \\
\hline 2 & Good Governance (Y2) & 0,723 & Kuat \\
\hline
\end{tabular}

Berdasarkan hasil perhitungan seperti terlihat pada Tabel 4 dapat dinyatakan nilai $R$-Square variabel Kualitas Layanan Pengadaan (Y1) sebesar 0,596. Angka tersebut dapat diinterpretasikan bahwa 59,6\% variabel Kualitas Layanan Pengadaan dijelaskan oleh variabel E-procurement dan Komitmen Pegawai, sedangkan 40,4\% variabel Kualitas Layanan Pengadaan dijelaskan oleh variabel lain di luar model penelitian. Hubungan antara variabel independen 
terhadap variabel dependen adalah moderat. Demikian juga variabel good governance memiliki nilai $R$-Square sebesar 0,723. Angka ini diinterpretasikan bahwa 72,3\% variabel Good Governance dijelaskan oleh variabel Electronic Procurement, Komitmen Pegawai, dan Kualitas Layanan Pengadaan, sedangkan 27,7\% variabel Good Governance dijelaskan oleh variabel lain di luar model penelitian. Dalam hal ini, hubungan antara variabel independen terhadap variabel dependen adalah kuat.

Selain menggunakan R-Square, Goodness of Fit Model juga diukur menggunakan $Q$-Square Predictive Relevance untuk model struktural yang mengukur seberapa baik nilai observasi dihasilkan oleh model dan juga estimasi parameternya. Perhitungan Goodness of Fit Model adalah sebagai berikut:

$$
\begin{aligned}
\mathrm{Q}^{2} & =1-\left(1-\mathrm{R}_{1}{ }^{2}\right)\left(1-\mathrm{R}_{2}{ }^{2}\right) \\
& =1-\left(1-(0,596)^{2}\right)\left(1-(0,723)^{2}\right) \\
& =0,692
\end{aligned}
$$

Berdasarkan perhitungan di atas, 69,2\% variabel Good Governance dijelaskan oleh variabel Electronic Procurement, Komitmen Pegawai, dan Kualitas Layanan Pengadaan, sedangkan sisanya sebesar 30,8\% dijelaskan oleh variabel lain yang tidak masuk dalam model penelitian seperti misalnya variabel inprastuktur penunjang sistem. Model yang dibangun mempunyai nilai Predictive Relevance atau tingkat prediksi yang cukup akurat.

\section{3) Uji Pengaruh Langsung}

Pengujian path coefficients dilakukan untuk menguji pengaruh variabel dalam model sebagaimana tertuang pada Tabel 5. Dari hasil pengujian hipotesis (Inner Model) pada Tabel 5 semua pengaruh langsung dapat dinyatakan signifikan 
karena memiliki $T$ Statistics $>1,990$. Hubungan variabel tersebut dapat juga diilustrasikan melalui diagram jalur seperti yang disajikan pada Gambar 3.

\section{Tabel 5}

Result for Inner Model (Pengaruh Langsung)

\begin{tabular}{|c|c|c|c|c|c|}
\hline No & Pengaruh Langsung & $\begin{array}{c}\text { Original } \\
\text { Sample }\end{array}$ & $\begin{array}{c}\text { Standard } \\
\text { Deviation }\end{array}$ & $T$ Statistics & Keterangan \\
\hline 1 & 2 & 3 & 4 & 5 & 6 \\
\hline 1 & $\begin{array}{l}\text { Electronic Procurement } \rightarrow \\
\text { Kualitas Layanan Pengadaan }\end{array}$ & 0,324 & 0,096 & 3,395 & Signifikan \\
\hline 2 & $\begin{array}{l}\text { Komitmen Pegawai } \rightarrow \\
\text { Kualitas Layanan Pengadaan }\end{array}$ & 0,520 & 0,097 & 5,342 & Signifikan \\
\hline 3 & $\begin{array}{l}\text { Electronic Procurement } \rightarrow \\
\text { Good Governance }\end{array}$ & 0,251 & 0,092 & 2,735 & Signifikan \\
\hline 4 & $\begin{array}{l}\text { Komitmen Pegawai } \rightarrow \text { Good } \\
\text { Governance }\end{array}$ & 0,404 & 0,112 & 3,608 & Signifikan \\
\hline 5 & $\begin{array}{l}\text { Kualitas Layanan Pengadaan } \\
\rightarrow \text { Good Governance }\end{array}$ & 0,299 & 0,107 & 2,788 & Signifikan \\
\hline
\end{tabular}

Sumber: Data primer (2017)

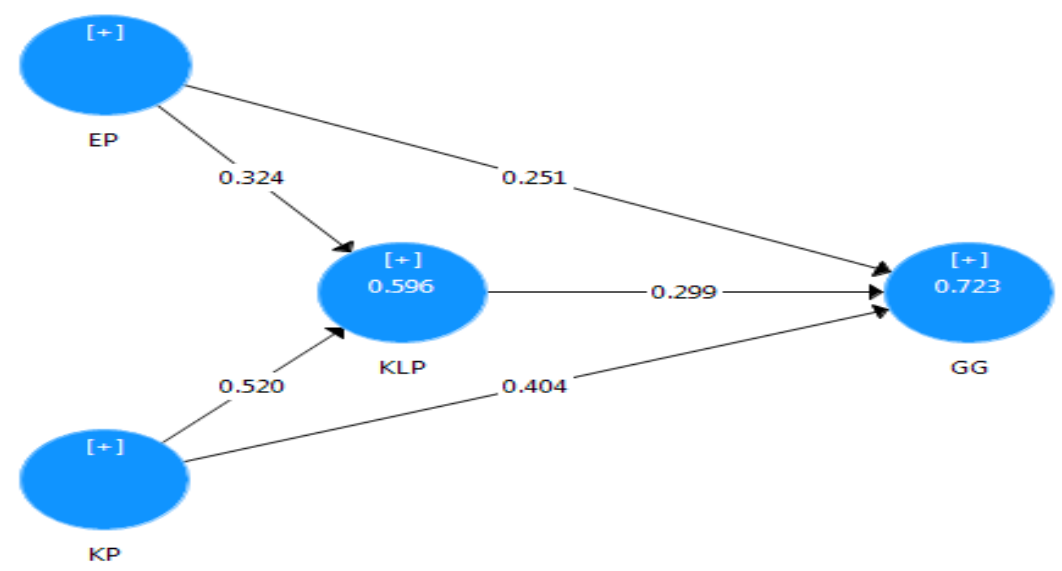

Gambar 3

Koefisien Jalur Hubungan Antar Variabel

Variabel endogen Kualitas Layanan Pengadaan dalam Gambar 3 dipengaruhi oleh variabel eksogen Electronic Procurement dan Komitmen Pegawai. Komitmen Pegawai dengan koefisien jalur sebesar 0,520 memiliki pengaruh yang lebih besar terhadap Kualitas Layanan Pengadaan dari pada variabel Electronic Procurement yang memiliki koefisien jalur 0,324. Variabel 
endogen Good Governance dipengaruhi oleh variabel eksogen Electronic Procurement dan Komitmen Pegawai serta variabel antara Kualitas Layanan Pengadaan. Komitmen Pegawai dengan koefisien jalur sebesar 0,404 memiliki pengaruh yang paling besar terhadap Good Governance dibanding variabel Electronic Procurement dan Kualitas Layanan Pengadaan yang memiliki koefisien jalur masing-masing sebesar 0,251 dan 0,299.

4) Pengaruh Tidak Langsung atau Mediasi

Berdasarkan hasil indirect effect pengaruh variabel independen terhadap variabel dependen melalui variabel mediasi hasilnya disajikan pada Tabel 6 . Berdasarkan Tabel 6 dapat dijelaskan bahwa variabel Kualitas Layanan Pengadaan (Y1) signifikan memediasi pengaruh antara E-procurement (X1) dan Komitmen Pegawai (X2) terhadap good governance (Y2).

Tabel 6

Hasil Pengujian Pengaruh Tidak Langsung

\begin{tabular}{|c|c|c|c|c|c|}
\hline $\begin{array}{c}\text { Hubungan } \\
\text { Variabel }\end{array}$ & $\begin{array}{l}\text { Original } \\
\text { Sampel }\end{array}$ & $\begin{array}{l}\text { Variabel } \\
\text { Mediasi }\end{array}$ & $\begin{array}{l}\text { Standard } \\
\text { Deviation }\end{array}$ & T-Statistic & P Value \\
\hline $\mathrm{X} 1 \rightarrow \mathrm{Y} 2$ & 0,097 & $\mathrm{Y} 1$ & 0,046 & 2,099 & 0,036 \\
\hline $\mathrm{X} 2 \rightarrow \mathrm{Y} 2$ & 0,156 & Y1 & 0,065 & 2,397 & 0,017 \\
\hline
\end{tabular}

5) Pembahasan Hasil Penelitian

(1) Pengaruh Langsung Electronic Procurement Terhadap Kualitas Layanan Pengadaan

Pengaruh langsung pengelolaan keuangan daerah terhadap SAKIP memiliki koefisien jalur (original sample) sebesar 0,324. Hal ini berarti, apabila E-procurement semakin baik maka Kualitas Layanan Pengadaan juga semakin baik/meningkat. Penerapan eprocurement harus dilihat sebagai upaya untuk 
meningkatkan tujuan pengadaan, yaitu kualitas, ketepatan waktu, biaya, meminimalkan resiko bisnis, keuangan dan teknis; memaksimalkan kompetisi dan mempertahankan integritas.

Hasil penelitian ini sesuai dengan penelitian Adimaja (2010). Hasil penelitian menunjukkan adanya pengaruh positif penerpan eprocurement terhadap kualitas pelayanan publik. Hal ini dapat diartikan bahwa semakin sempurna penerapan e-procurement maka akan semakin baik pelayanan publik yang dilaksanakan pihak lembaga penyelenggara.

(2) Pengaruh Langsung Komitmen Pegawai Terhadap Kualitas Layanan Pengadaan

Pengaruh langsung Komitmen Pegawai terhadap Kualitas Layanan Pengadaan memiliki koefisien jalur (original sample) sebesar 0,520. Hal ini berarti, apabila Komitmen Pegawai semakin baik maka Kualitas Layanan Pengadaan juga semakin baik/meningkat. Peran sentral terutama unsur sumber daya manusia di setiap organisasi sangat dibutuhkan. Tidak terkecuali pada instansi pemerintah. Sebagai pelaksana tugas dan penyedia layanan kepada masyarakat diharapkan pemerintah mampu menggunakan dan memiliki aparatur atau pegawai yang cakap dan bertanggung jawab akan tugas dan lembaganya untuk pencapaian layanan yang semakin baik.

Hasil penelitian ini sejalan dengan penelitian yang dilakukan oleh Hidayat, M. (2010). Hasil penelitian menyimpulkan Tiga model komponen komitmen, menggambarkan multidimensi dari membangun komitmen, dalam kaitannya dengan kualitas pelayanan lebih mendukung argumen bahwa tidak 
semua bentuk komitmen secara signifikan berkaitan dengan kualitas pelayanan. Komitmen pegawai pengadaan barang/jasa pada Pemerintah Provinsi Bali dalam upaya percepatan pelaksanaan pengadaan barang dan jasa secara elektronik berpengaruh juga terhadap tingkat capaian efisiensi anggaran dan partisipasi penyedia barang/jasa yang dari tahun ke tahun semakin meningkat.

(3) Pengaruh Langsung Electronic Procurement Terhadap Good Governance

Pengaruh langsung E-procurement terhadap good governance memiliki koefisien jalur (original sample) sebesar 0,251. Hal ini berarti, apabila $E$ procurement semakin baik maka Good Governance juga semakin baik/meningkat. Penerapan eprocurement harus dilihat sebagai upaya untuk meningkatkan tujuan pengadaan, yaitu kualitas, ketepatan waktu, biaya, meminimalkan resiko bisnis, keuangan dan teknis, memaksimalkan kompetisi dan mempertahankan integritas.

Hasil ini sejalan dengan penelitian yang dikukan oleh Rieska Maharani \& Ardi Hamzah (2008). Hasil penelitian menyimpulkan bahwa prinsip efisiensi, efektifitas, persaingan, transparansi, keadilan dan tanggung jawab dalam $e$ procurement berpengaruh signifikan terhadap good governance. Pada Pemerintah Provinsi Bali dapat dijelaskan bahwa penerapan e-procurement semakin baik maka akan berpengaruh positif juga terhadap terwujudnya good governance.

(4) Pengaruh Langsung Komitmen Pegawai Terhadap Good Governance

Pengaruh langsung Komitmen Pegawai terhadap good governance memiliki koefisien jalur (original sample) sebesar 0,404. Hal ini berarti, apabila Komitmen Pegawai semakin baik maka Good Governance juga semakin 
baik/meningkat. Komitmen Pegawai yang baik dimulai dari pelaksanaan layanan prima yang diberikan kepada masyarakat yang memanfaatkan jasa dimaksud dalam hal ini adalah layanan pengadaan barang/jasa. Komitmen Pegawai semakin baik memberikan jaminan bahwa tidak terjadi layanan pemerintah tidak sesuai dengan penerapan peraturan yang berlaku penyelenggaraan urusan pemerintahan.

Hasil ini sesuai dengan penelitian Wiratno Adi, dkk. (2013) yang menunjukkan komitmen organisasi berpengaruh positif dan signifikan terhadap penerapan good governance, ini menunjukan bahwa komitmen organisasi memberikan kontribusi yang signifikan terhadap penerapan good governance di tempat penelitian.

(5) Pengaruh Kualitas Layanan Pengadaan Terhadap Good Governance

Pengaruh langsung Kualitas Layanan Pengadaan terhadap good governance memiliki koefisien jalur (original sample) sebesar 0,299. Hal ini berarti, apabila Kualitas Layanan Pengadaan semakin baik maka Good Governance juga semakin baik/meningkat. Kualitas pelayanan pengadaan barang dan jasa adalah keunggulan pelayanan yang diberikan kepada pengguna layanan untuk mendapatkan barang dan jasa yang diperlukan sesuai dengan kebutuhan penggunaannnya yang telah ditentukan, dilihat dari kualitas, kuantitas, waktu pengiriman dan harga yang terjangkau.

Hasil penelitian ini sesuai dengan penelitian Yanto Heryanto (2014). Hasil penelitian menunjukkan bahwa ada beberapa pertimbangan mengapa peningkatan kualitas pelayanan publik menjadi strategis untuk memulai menerapkan good governance. Pelayanan publik selama ini menjadi ranah dimana Pemerintah 
I Made Budi Adiana, I Nyoman Mahaendra Yasa, dan I Gede Wardana. Pengaruh Electronic...

berinteraksi dengan masyarakat. Ini berarti jika terjadi perubahan yang signifikan pada kualitas pelayanan publik, dengan sendirinya dapat dirasakan manfaatnya secara langsung oleh masyarakat luas.

(6) Pengaruh Tidak Langsung Electronic Procurement terhadap Good Governance melalui Kualitas Layanan Pengadaan

Hasil penelitian pengaruh tidak langsung E-procurement terhadap Good Governance melalui Kualitas Layanan Pengadaan menunjukkan pengaruh yang positif dan signifikan. Ini berarti bahwa variabel E-procurement berpengaruh positif dan signifikan secara tidak langsung terhadap Good Governance melalui Kualitas Layanan Pengadaan. Apabila E-procurement semakin baik maka Good Governance juga semakin baik/meningkat melalui Kualitas layanan Pengadaan.

Hasil penelitian ini sesuai dengan penelitian Resti Mega Artantri Luh Putu, dkk. (2015) tentang Peran E-Procurement terhadap Pencegahan Fraud pada Pengadaan Barang/Jasa Pemerintah di Pulau Lombok. Peran e-procurement terbukti dapat meningkatkan transparansi, meningkatkan akuntabilitas, mendukung monitoring dan audit, memberikan informasi yang real time serta memberikan pengetahuan yang luas bagi masyarakat mengenai proses pengadaan barang/jasa. E-procurement juga dapat mengurangi inefisiensi pengadaan dengan memberikan manfaat yang lebih besar dibandingkan dengan biaya yang dikeluarkan. 
(7) Pengaruh Tidak Langsung Komitmen Pegawai terhadap Good Governance melalui Kualitas Layanan Pengadaan

Hasil penelitian pengaruh tidak langsung Komitmen Pegawai terhadap Good Governance melalui Kualitas Layanan Pengadaan menunjukkan pengaruh yang positif dan signifikan. Ini berarti bahwa variabel Komitmen Pegawai berpengaruh positif dan signifikan secara tidak langsung terhadap Good Governance melalui Kualitas Layanan Pengadaan. Apabila Komitmen Pegawai semakin baik maka Good Governance juga semakin baik/meningkat melalui variabel Kualitas Layanan Pengadaan.

Hasil penelitian ini sejalan dengan penelitian Wiratno Adi, dkk. (2013), bahwa komitmen organisasi berpengaruh positif dan signifikan terhadap penerapan good governance, ini menunjukan bahwa komitmen organisasi dalam hal ini adalah komitmen pegawai memberikan kontribusi yang signifikan terhadap penerapan good governance di tempat penelitian.

\section{SIMPULAN DAN SARAN}

Berdasarkan hasil dan pembahasan, maka dapat disimpulkan bahwa:

1) Electronic Procurement dan Komitmen Pegawai berpengaruh positif dan signifikan terhadap Kualitas Layanan Pengadaan pada Pemerintah Provinsi Bali. Artinya bahwa semakin baik Electronic Procurement (efisien, adil/tidak diskriminatif dan akuntabel) maka Kualitas Layanan Pengadaan juga akan semakin baik/meningkat. Semakin baik penerapan Komitmen Pegawai (afektif, berkesinambungan dan normatif) maka Kualitas Layanan Pengadaan juga akan semakin baik/meningkat. 
2) Electronic Procurement, Komitmen Pegawai, dan Kualitas Layanan Pengadaan berpengaruh positif dan signifikan terhadap Good Governance pada Pemerintah Provinsi Bali. Artinya bahwa semakin baik Electronic Procurement (efisien, adil/tidak diskriminatif dan akuntabel) maka Good Governance juga akan semakin baik/meningkat. Semakin baik penerapan Komitmen Pegawai (afektif, berkesinambungan dan normatif) maka Good Governance juga akan semakin baik/meningkat. Semakin baik Kualitas Layanan Pengadaan (reability, responsiveness, dan assurance) maka Good Governance juga akan semakin baik/meningkat.

3) Electronic Procurement dan Komitmen Pegawai berpengaruh positif dan signifikan secara tidak langsung terhadap Good Governance pada Pemerintah Provinsi Bali melalui Kualitas Layanan Pengadaan. Artinya bahwa semakin baik Electronic Procurement dan Kualitas Layanan Pengadaan maka Good Governance Pemerintah Provinsi Bali juga akan semakin baik/meningkat. Semakin baik Komitmen Pegawai dan Kualitas Layanan Pengadaan maka Good Governance Pemerintah Provinsi Bali juga akan semakin baik/meningkat.

Dengan adanya hubungan positif antara E-procurement, Komitmen Pegawai, dan Kualitas Layanan Pengadaan terhadap Good Governance, diharapkan Pemerintah Provinsi Bali terus meningkatkan kualitas layanan pengadaan kepada masyarakat. Electronic Procurement pada Pemerintah Provinsi Bali dapat ditingkatkan dengan cara menciptakan kompetisi yang adil bagi penyedia barang/jasa yang mengikuti proses pelelangan barang dan jasa, dan 
memberikan kepastian informasi mengenai seluruh program dan kegiatan Pemerintah Provinsi Bali kepada seluruh penyedia barang/jasa. Komitmen Pegawai Pengadaan Barang/Jasa pada Pemerintah Provinsi Bali dapat ditingkatkan dengan cara meningkatkan keberpihakan aparatur LPSE dan ULP/Pokja Provinsi Bali agar adil/tidak diskriminatif dalam pelayanan, meningkatkan transparansi pada ketentuan dan informasi dalam pelayanan dan akuntabel sesuai dengan aturan dan ketentuan yang terkait dengan pengadaan barang/jasa, atas dasar karena ikatan psikologis dan kebutuhan pegawai sendiri serta kewajiban tugas terhadap lembaga.

Kualitas Layanan Pengadaan pada Pemerintah Provinsi Bali dapat ditingkatkan dengan cara aparatur LPSE dan ULP/Pokja Provinsi Bali dalam pelayanan memberikan solusi terbaik dan bahkan melampaui harapan penyedia barang/jasa, memberikan layanan terbaik dengan mempertimbangkan aspek resiko dan prinsip kehati-hatian, memberikan informasi tepat dan akurat terkait $e$ procurement, meningkatkan pengetahuan dan pemahaman yang baik tentang aturan-aturan pengadaan barang/jasa secara elektronik dan memberikan bantuan/pelayanan kepada penyedia tanpa membeda-bedakan.

Good Governance pada Pemerintah Provinsi Bali dapat ditingkatkan dengan cara selalu memperbaharui informasi yang berhubungan dengan perubahan layanan serta informasi pelaksanaan program pembangunan, meningkatkan arus informasi, bekerja sama dengan media massa dan lembaga non pemerintahan, meningkatkan informasi mengenai kejelasan biaya baik kewajaran dan kepastian biaya layanan yang dibebankan sesuai dengan ketentuan dan 
peraturan yang berlaku, meningkatkan fasilitas forum untuk menampung partisipasi masyarakat yang representatif, jelas arahnya dan dapat dikontrol, bersifat terbuka dan inklusif, ditempatkan sebagai mimbar masyarakat mengekspresikan keinginannya atas penyelenggaraan pemerintahan, dan meningkatkan peran Pemerintah Provinsi Bali dalam mengakomodir aspirasi masyarakat..

\section{REFERENSI}

Adiningsih, Tuti. 2013. "Efisiensi Implementasi E-Procurement pada Proses Pengadaan Barang dan Jasa di Pemerintah Daerah (Studi pada Pemerintah Kota Yoyakarta Tahun 2008-2012)” (tesis). Yogyakarta: Universitas Gadjah Mada.

Adimaja. 2010. "Pengaruh Penerapan E-Procurement terhadap Peningkatan Kualitas Kinerja dan Pelayanan Publik pada Dinas Pendidikan Provinsi Kepulauan Riau" (tesis). Jakarta: Universitas Terbuka.

Agus Dwiyanto. 2008. Mewujudkan Good Governance Melalui Pelayanan Publik. Yogyakarta: Gadjah Mada University Press.

Aldino Septa Nugraha. 2012. Penerapan E-Procurement di Instansi Pemerintah berdasarkan Peraturan Presiden Nomor 54 Tahun 2010 tentang Pengadaan Barang/Jasa.. Universitas Gunadarma.

Ambar Teguh Sulistiyani. 2011. Memahami Good Governance: Dalam Perspektif Sumber Daya Manusia. Yogyakarta: Gava Media.

Andriyani, Susan. 2012. Analisis Efektifitas Hukum Dalam Penerapan Pengadaan Barang dan Jasa Secara Elektronik (E-Procurement) Serta Peranan Lembaga Pengawas Terhadap Pengadaan Barang dan Jasa Pemerintah. Jakarta.

Aryani, D., \& Rosinta, F. 2010 tentang Pengaruh Kualitas Layanan terhadap Kepuasan Pelanggan dalam Membentuk Loyalitas Pelanggan. Jurnal Ilmu Administrasi dan organisasi, Vol 17, No.2, Mei-Agustus 2010, Hal. 114126.

Damayanti A., \& Hamzah A. 2008. Pengaruh Penerapan Sebagai Alat Pengendalian Pengadaan Barang/Jasa Pada Pemerintah Kota Surabaya EProcurement terhadap terwujudnya Good Governance. Jurnal Infestasi, Vol 4, No.2, Desember 2008, Hal. 125-144. 
Davila, A., Gupta, M., Palmer, R. 2003. Moving procurement systems to the internet: the adoption and use of e-Procurement technology models. [Online]. Tersedia di: http://www.isiarticles.com/bundles/Article/ pre/pdf/16855.pdf [diunduh: 23 September 2017].

Deddy S.B. \& Dadang Solihin. 2004. Otonomi Penyelenggaraan Pemerintah Daerah. Jakarta: PT. Gramedia Pustaka.

Eko Prasojo \& Teguh Kurniawan. 2008. Reformasi Birokrasi dan Good Governance: Kasus Best Practices dari Sejumlah Daerah di Indonesia. Jakarta: Universitas Indonesia.

Ferdinand. 2006. Metode Penelitian Manajemen: Pedoman Penelitian untuk skripsi, Tesis dan Disertai Ilmu Manajemen. Semarang: Universitas Diponegoro.

Ghozali, Imam. 2011. Structural Equation Modelin Metode Alternative dengan Partial Least Square. Semarang: Badan Penerbit Universitas Diponegoro.

Gubernur Bali. 2009. Peraturan Gubernur Bali Nomor 53 Tahun 2009 tentang Pembentukan Unit Layanan Pengadaan (ULP) Barang/Jasa Pemerintah di Lingkungan Pemerintah Provinsi Bali.

Gubernur Bali. 2011. Peraturan Gubernur Bali Nomor 36 Tahun 2011 tentang Pembentukan Unit Layanan Pengadaan (ULP) Barang/Jasa Pemerintah di Lingkungan Pemerintah Provinsi Bali.

Gubernur Bali. 2016. Peraturan Gubernur Bali Nomor 131 Tahun 2016 tentang Kedudukan, Susunan Organisasi, Tugas dan Fungsi, serta Tata Kerja Sekretariat Daerah Provinsi Bali.

Heryanto, Y. 2014. Implementasi Good Governance terhadap Peningkatan Pelayanan Publik di Indonesia. Jurnal Logika, Vol. XII, No. 3, Tahun 2014.

Hidayat, M. 2010. Analisis Komitmen (Affective, Continuance dan Normative) Terhadap Kualitas Pelayanan Pengesahan STNK Kendaraan Bermotor (Studi Empiris pada Kantor Bersama Samsat di Propinsi Kalimantan Timur). Jurnal Manajemen dan Kewirausahaan, Vol. 12, (2), 11-23.

Indrajit, Richardus Eko (2005). E-Government in action. Yogyakarta: Andi Offset.

Ismail, Sachlan Effendi, dan Moh. Sa'id. 2014. Pengaruh Kepemimpinan, Loyalitas Karyawan dan Kinerja Karyawan terhadap Kualitas Pelayanan Unit Layanan Pengadaan Barang/Jasa. Surakarta: Universitas Slamet Riyadi. 
Lewis, Carol W. and Stuart C. Gilman. 2005. The Ethics Challenge in Public Service: A Problem-Solving Guide. Market Street, Jossey-Bass: San Fransisco.

Lori, Pramasari Kadek. 2014. Penerapan Sistem E-Procurement Dalam Tata Kelola Pengadaan Barang dan Jasa (Studi Kasus: Badan Layanan Pengadaan Secara Elektronik (LPSE) Kota Denpasar). Denpasar.

Maharani, R. \& Hamzah, A. 2008. Pengaruh E-Procurement terhadap terwujudnya Good Governance. Jurnal Infestasi, Vol 4, No.1, Juni 2008, Hal. 1-13.

Nazir, Moh., 2005. Metode Penelitian. Jakarta: Ghalia Indonesia.

Nightisabha, Ita Akyuna. 2009. Persepsi Pengguna Layanan Pengadaan Barang dan Jasa Pada Pemerintah Kota Yogyakarta Terhadap Implementasi Sistem E-Procurement. [Online]. Tersedia di: http://www. media.neliti.com/media/publications/85320-ID-persepsi-penggunalayanan-pengadaan-bara.pdf [diunduh: 23 September 2017].

Panayiotou, N.A., Gayaialis, S.P., Tatsiopoulos, I.P. 2004. An E-procurement system for governmental purchasing. International Journal of Production Economics, Vol. 90, Hal. 79-102.

Pemerintah Provinsi Bali. 2017. Peraturan Daerah Provinsi Bali Nomor 2 Tahun 2017 tentang Perubahan Atas Peraturan Daerah Nomor 1 Tahun 2014 tentang Rencana Pembangunan Jangka Menengah Daerah Provinsi Bali Tahun 2013-2018

Pemerintah Republik Indonesia. 2004. Undang-Undang Republik Indonesia Nomor 32 Tahun 2004 tentang Pemerintahan Daerah.

Pemerintah Republik Indonesia. 2008. Undang-Undang Republik Indonesia Nomor 12 Tahun 2008 tentang Perubahan Kedua Atas Undang-Undang Nomor 32 Tahun 2004 tentang Pemerintahan Daerah.

Pradana, Hidayat Adi. 2014. Evaluasi Penerapan Electronic Procurement pada Fakultas Ilmu Sosial dan Ilmu Politik Universitas Brawijaya Malang dalam Upaya Mewujudkan Good Governance. Malang.

Presiden Republik Indonesia. 2003. Keputusan Presiden Republik Indonesia Nomor 80 Tahun 2003 tentang Pedoman Pelaksanaan Pengadaan Barang/Jasa Pemerintah.

Presiden Republik Indonesia. 2006. Peraturan Presiden Republik Indonesia Nomor 8 Tahun 2006 tentang Perubahan keempat atas Keputusan Presiden Nomor 80 Tahun 2003 tentang Pedoman Pelaksanaan Pengadaan Barang/Jasa Pemerintah. 
Presiden Republik Indonesia. 2010. Peraturan Presiden Republik Indonesia Nomor 54 Tahun 2010 tentang Pengadaan Barang/Jasa Pemerintah.

Presiden Republik Indonesia. 2015. Peraturan Presiden Republik Indonesia Nomor 4 Tahun 2015 tentang Perubahan Keempat Atas Peraturan Presiden Nomor 54 Tahun 2010 Tentang Pengadaan Barang/Jasa Pemerintah.

Rahmawan, dkk. 2015. Pengaruh Implementasi Sistem Pengadaan Secara Elektronik (E-Procurement) terhadap Fraud Pengadaan Barang/Jasa Pemerintah (Studi pada Satuan Kerja Perangkat Daerah Kabupaten Magetan). Jurnal Administrasi Publik (JAP), Vol. 3, No.11, Hal. 19051911.

Resti Mega Artantri Luh Putu, dkk. 2015. Peran E-Procurement terhadap Pencegahan Fraud pada Pengadaan Barang/Jasa Pemerintah di Pulau Lombok. Jurnal Akutansi, Vol. 10, No. 1.

Santoso, Singgih. 2014. Statistik Multivariat Edisi Revisi. Jakarta: PT. Elex Media Komputindo.

Sedarmayanti. 2004. Good Governance (Kepemerintahan yang Baik), Ed.2. Bandung: Mandar Maju.

Sinambela, dkk. 2008. Reformasi Pelayanan Publik, Teori, Kebijakan dan Implementasi. Jakarta: Bumi Aksara.

Sopiah. 2008. Perilaku Organisasi. Yogyakarta; Andi.

Sucahyo, Y. G. \& Ruldeviyani, Y. 2009. Inovasi Layanan Publik melalui Eprocurement. Jakarta: LKPP.

Sudjana, Nana. 1989. Tuntunan Penyusunan Karya Ilmiah. Bandung: Tarsito.

Sugiyono. 2008. Metode Penelitian Administrasi. Bandung: Alfabeta.

Sugiyono. 2009. Metode Penelitian Bisnis (Pendekatan Kuantitatif, Kualitatif, dan $R \& D)$. Bandung: Alfabeta.

Tatsis,V., Mena,C., Van Wassenhove, L.N., Whicker,L. 2006. Procurement in the Greek Food and Drink Industry: Drivers and Impediments. [Online]. Tersedia di: http://www.isiarticles.com/bundles/Article/pre/pdf/ 16910.pdf [diunduh: 23 September 2017].

Valerie, A. dkk. 1990. Delivering Quality Service: Balancing Customer Perceptions and Expectations. New York: The Free Press. 
I Made Budi Adiana, I Nyoman Mahaendra Yasa, dan I Gede Wardana. Pengaruh Electronic...

Wiratno Adi, dkk. 2013. Pengaruh Budaya Organisasi, Gaya Kepemimpinan, Komitmen Organisasi dan Pengendalian Intern Terhadap Penerapan Good Governance Serta Implikasinya Pada Kinerja. Journal dan Proceeding, Vol. 1, No. 1.

Zweers, K. And Plaque, K. 2001. Elektronik Government. From an Organisation based Perspektive Toward a Client Oriented Approach. 